\title{
Geomagnetic observations on Tristan da Cunha, South Atlantic Ocean
}

\author{
Jürgen Matzka $\left({ }^{1}\right)$, Nils Olsen $\left({ }^{2}\right)$, Cathrine Fox Maule $\left({ }^{1}\right)$, Lars William Pedersen $\left({ }^{1}\right)$, \\ Alan M. Berarducci $\left({ }^{3}\right)$ and Susan Macmillan $\left({ }^{4}\right)$ \\ (1) Danish Meteorological Institute, Copenhagen, Denmark \\ ${ }^{(2)}$ DTU-Space, National Space Institute of Denmark, Copenhagen, Denmark \\ $\left(^{3}\right)$ United States Geological Survey, National Geomagnetism Program, Golden, USA \\ $\left({ }^{4}\right)$ British Geological Survey, Edinburgh, United Kingdom
}

\begin{abstract}
Few geomagnetic ground observations exist of the Earth's strongest core field anomaly, the South Atlantic Anomaly (SAA). The geomagnetic repeat station on the island Tristan da Cunha, located half-way between South Africa and South America at $37^{\circ} 05^{\prime} \mathrm{S}, 12^{\circ} 18^{\prime} \mathrm{W}$, is therefore of crucial importance. We have conducted several sets of repeat station measurements during magnetically quiet conditions ( $\mathrm{Kp} 2 \mathrm{o}$ or less) in 2004. The procedures are described and the results are compared to those from earlier campaigns and to the predictions of various global field models. Features of the local crustal bias field and the solar quiet daily variation are discussed. We also evaluate the benefit of continuous magnetic field recordings from Tristan da Cunha, and argue that such a data set is a very valuable addition to geomagnetic satellite data. Recently, funds were set up to establish and operate a magnetometer station on Tristan da Cunha during the Swarm magnetic satellite mission (2011-2014).
\end{abstract}

Key words South Atlantic Anomaly - geomagnetic observatory - geomagnetic repeat station - Tristan da Cunha

\section{Introduction}

One of the largest gaps in the current distribution of geomagnetic ground observations is in the South Atlantic Ocean (fig. 1). However, this is a region of special interest due to its anomalous geomagnetic field behaviour: here exists the largest depression in the Earth's core field, called the South Atlantic Anomaly or

Mailing address: Dr. Jürgen Matzka, Remote Sensing and Geomagnetism, Danish Meteorological Institute, Lyngbyvej 100, DK-2100 Copenhagen, Denmark; e-mail: jmz@dmi.dk
SAA (indicated by the total field strength isoline for $30000 \mathrm{nT}$ in fig. 1). The SAA originates from inverse magnetic flux patches at the coremantle boundary mainly beneath South America and South Africa, which have developed over the last 200 years (Gubbins et al., 2006). It is the weakening of the geomagnetic field in the SAA that is in large part responsible for the present decline of Earth's magnetic field strength (Olsen et al., 2006, Hulot et al., 2007). A consequence of the low geomagnetic field intensity is the distortion of the inner van Allen radiation belt, causing a strong increase of radiation damage to low-Earth-orbiting satellites when passing through the SAA (Heirtzler et al., 2002).

Due to the lack of geomagnetic ground observations in the South Atlantic (fig. 1), the geomagnetic field in the SAA region is presently mainly determined from satellite-based measurements (e.g. Hulot et al., 2002; Olsen and Mandea, 2006). For a geophysical interpre- 


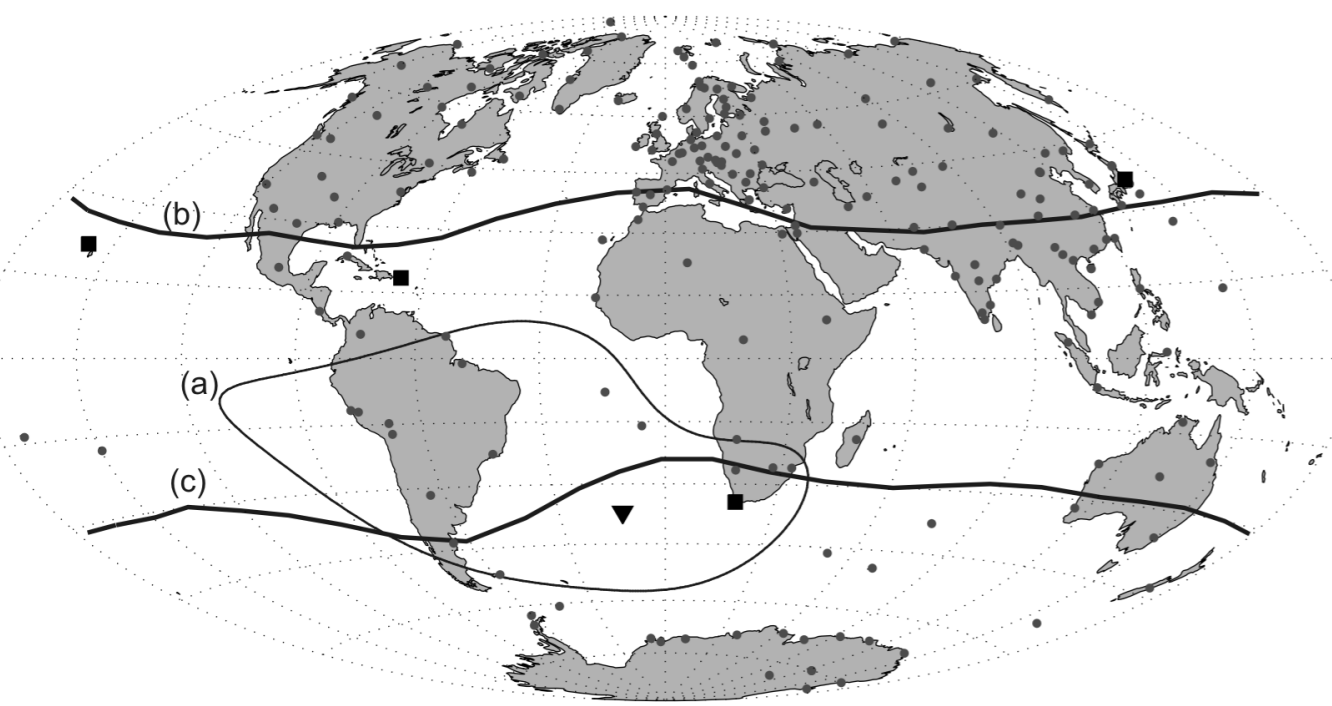

Fig. 1. Global distribution of geomagnetic observatories for 2008 (dots) and location of Tristan da Cunha (triangle). The South Atlantic Anomaly (SAA) is indicated by the $30000 \mathrm{nT}$ isoline (a) for total field strength calculated after the CHAOS model (Olsen et al., 2006). The northern (b) and southern (c) track of the solar quiet (Sq) current system foci are indicated as lines (computed from CM4, Sabaka et al., 2004). The four Dst-observatories are shown by squares.

tation, the geomagnetic data have to be separated into field contributions from the core, crust, ionosphere, and magnetosphere, plus fields due to currents induced in the Earth's mantle and the oceans. This separation can be achieved by comprehensive modelling (Sabaka et al., 2004), a process that, however, depends on the availability of simultaneous geomagnetic data from satellites and ground. Surface time series are currently not available for the central South Atlantic since there are no geomagnetic observatories within a circle of roughly $3000 \mathrm{~km}$ radius centred at $42^{\circ} \mathrm{S}, 15^{\circ} \mathrm{W}$. Only few islands are located within this circle, but the Tristan da Cunha group of islands with its main island Tristan da Cunha $\left(37^{\circ} 05^{\prime} \mathrm{S}, 12^{\circ} 18^{\prime} \mathrm{W}\right)$ is close to its centre. Geomagnetic measurements from that island will therefore make a significant contribution towards a more even distribution of geomagnetic ground stations in the South Atlantic.

At present, there is a geomagnetic repeat station on Tristan da Cunha, for which we report results for the year 2004 here. The purpose of a geomagnetic repeat station is to provide information about the secular variation for an area without geomagnetic observatories (Newitt et al., 1996). Time variation of the external geomagnetic field contributions should therefore be subtracted from repeat station measurements. Assuming that these variations are homogeneous over a larger area, variation data from a nearby geomagnetic observatory can be used to calculate a yearly mean value for the repeat station. Alternatively, an on-site variometer can be used at the repeat station to determine the quiet night time value of the geomagnetic field for a certain day at the repeat station (Newitt et al., 1996).

The current lack of continuously recorded geomagnetic ground station data from Tristan da Cunha is caused mainly by logistical challenges. The island has no airport and ships call infrequently. An additional problem is the volcanic nature of Tristan da Cunha, causing a significant local crustal bias and strong spatial gradients of the geomagnetic field.

The geomagnetic observatories within the 
SAA closest to Tristan da Cunha are Hermanus in South Africa (IAGA code HER, approximate distance: $2800 \mathrm{~km}$ ), Keetmanshoop in Namibia $(\mathrm{KMH}, 3100 \mathrm{~km}$ distance, see Korte et al. (2009) in this issue), St. Helena (STH, $2400 \mathrm{~km}$ distance, see Korte et al. (2009) in this issue), Ascension Island (IAGA code ASC, $3200 \mathrm{~km}$ distance, see Macmillan et al. (2009) in this issue), Vassouras in Brazil (IAGA code VSS, $3400 \mathrm{~km}$ distance) and Port Stanley on the Falkland Islands (PST, $3900 \mathrm{~km}$ distance). Observatories to the south of the SAA are located on Antarctica at a distance between 3500 and $4000 \mathrm{~km}$.

The dipole (geomagnetic) latitude of Tristan da Cunha of $32^{\circ} \mathrm{S}$ is similar to those of the socalled Dst-stations Hermanus (HER), Kakioka (KAK), Honolulu (HON) and San Juan (SJG), which are indicated in fig. 1. The Dst-stations are used to determine the Dst index, an estimate of the strength of the magnetospheric ring current. Additionally, the tracks of the equinoctial northern and southern foci of the solar quiet (Sq-)current system are shown in fig. 1. These were derived by calculating the focus of the Sqcurrent system for each hour of the day from the CM4 model (Sabaka et al., 2004). Both the Dst-stations and Tristan da Cunha are located close to these foci (fig. 1), where the Sq magnetic field variation is most pronounced in the magnetic east-west component. As the variations due to the magnetospheric ring current occur mainly in the magnetic north component, having ground-based stations close to these foci would allow for a better separation of the two contributions. A regional estimate in the SAA of both the ring current field (which shows a longitudinal dependency, e.g. Le et al., 2004) and the field from the Sq-current system would be an advantage for geomagnetic models, especially for comprehensive modelling (Sabaka $e t$ al., 2004). For this purpose, continuously recorded geomagnetic data from Tristan da Cunha would be necessary.

\section{Observational and computational methods}

We first describe the repeat station measurements obtained in 2004 on Tristan da Cunha.
The repeat station 'TT-2', also known as 'SAT TRI STA 069' or 'The Hillpiece' (Riddick, pers. comm.), was occupied on Sept. 27 and 29 by one of us (JM). For measurement of the magnetic declination and inclination, a nonmagnetic Zeiss theodolite Theo 020A with Bartington fluxgate probe (DI-flux) with 0.25 nT resolution was set up on a tripod $125 \mathrm{~cm}$ above the Corps of Engineers bronze disk «SAT TRI STA 069 TT-2 1968» on a hill (called the Hillpiece) on Tristan da Cunha. This bronze disk is a geodetic mark ( $37^{\circ} 04^{\prime} 52.465^{\prime \prime} \mathrm{S}, 12^{\circ}$ 19' 18.8571" W, $225.1 \mathrm{~m}$ altitude). We used the azimuth mark RM2 (a previous repeat station occupied in 1986) of azimuth of $18^{\circ} 03^{\prime} 20^{\prime \prime}$ and distance of approximately $1.9 \mathrm{~km}$ to TT-2 (Riddick, pers. comm.). During the declination and inclination measurements, the total field was measured with an Elsec 770 proton precession magnetometers (PPM) on a remote site (called RM1, previously occupied in 2001) approximately $2 \mathrm{~m}$ above a brass disk located 9.5 $\mathrm{m}$ north-east of TT-2. To determine the difference in total field between RM1 and TT-2, a second Elsec 770 PPM was used to measure the total field simultaneously at the remote site RM1 and at exactly the same location as the DIflux. This was done prior to and after the DIflux measurements.

Measurements with the DI-flux followed the scheme for absolute measurements outlined in Jankowski and Sucksdorff (1996), with readings in four different positions for declination and inclination. Note, however, that the formula for inclination I on p. 96 in Jankowski and Sucksdorff (1996) is only valid in the northern hemisphere and has to be adjusted for the negative inclination on Tristan da Cunha by subtracting $180^{\circ}$ (e.g. Newitt et al., 1996). Also note the discussion on sensor misalignment and sensor offset described in Matzka and Hansen (2007). During the final inclination measurement on Sept. 29, the theodolite was frequently exposed to changing wind conditions, and vibrations of the automatic index of the Zeiss Theo 020A (a pendulum that indicates the vertical) made readings of the vertical circle tedious, but with no obvious degradation of accuracy. The results were checked for consistency by calculating sensor misalignment and sensor 


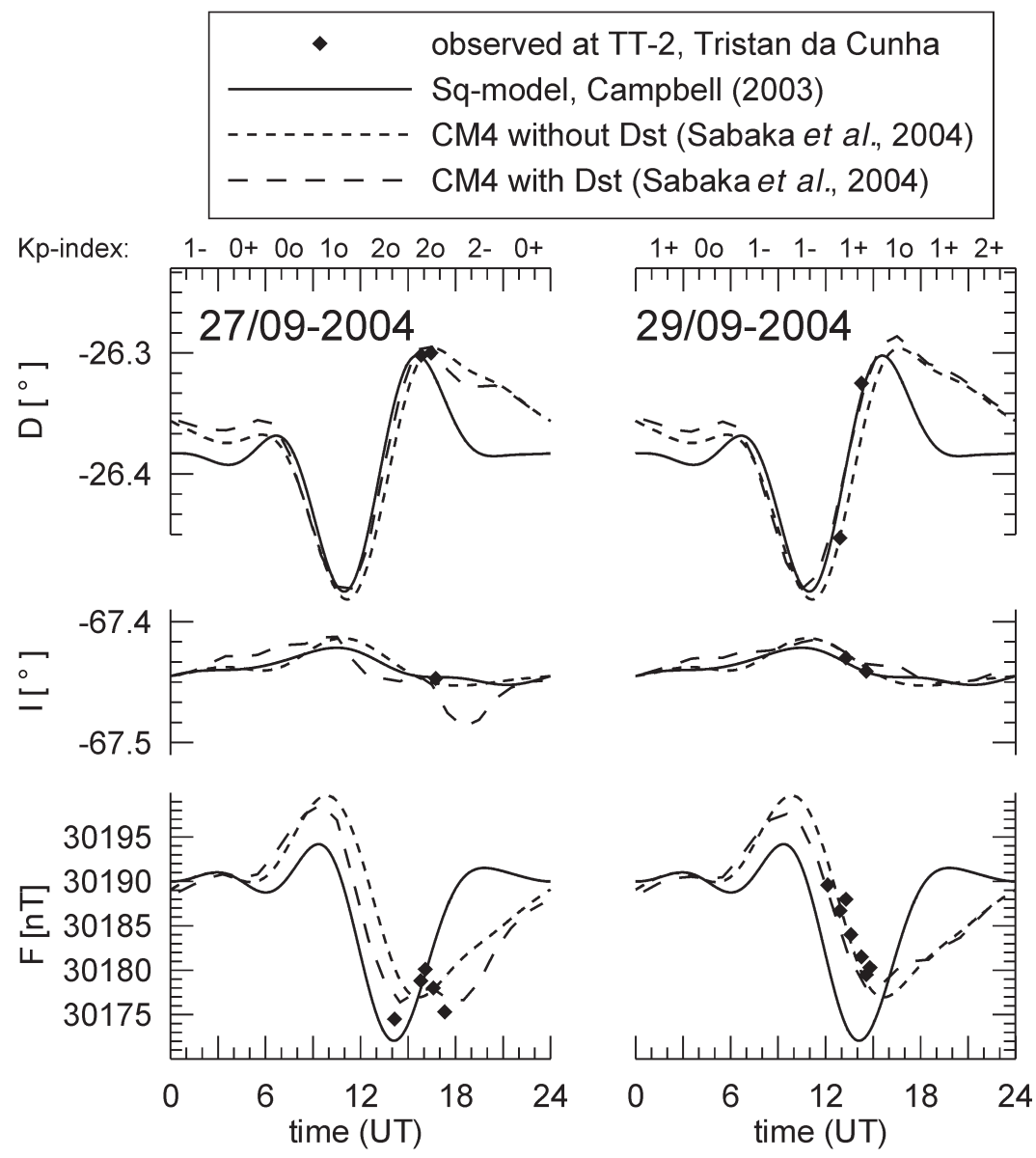

Fig. 2. Declination (D), inclination (I) and field strength (F) observations (diamonds) at TT-2, Tristan da Cunha, compared to three models (see text). Kp-values for the corresponding three-hour intervals are indicated at the top of the graph. Campbell's (2003) Sq-model is shown as full lines, geomagnetic variations are calculated from CM4 with Dst (long dashed) and without Dst (short dashed).

offset between successive measurements; they do not change by more then 1' and $3 \mathrm{nT}$, respectively. Azimuth mark readings were performed prior to and after declination measurements and do not vary by more than 0.1 '. Two independent absolute inclination results can be determined from the four-positions measurements scheme (Jankowski and Sucksdorff, 1996); they differ for the three inclination measurements by $0.3^{\prime}, 0.4^{\prime}$ and $0.5^{\prime}$, respectively. This suggests a systematic difference of the order of $0.4^{\prime}$, which can be explained by field gradients in the vicinity of the theodolite. The total field difference measured between TT- 2 and RM1 was of the order of $250 \mathrm{nT}$ and we estimate from our repeatedly conducted simultaneous measurements on TT-2 and RM1 that this does not change by more than $0.5 \mathrm{nT}$ during one set of DI-measurements.

Both the determination of the field direction and the field strength was conducted to achieve absolute values. From the above mentioned quality checks we estimate that our data have an accuracy of about $0.3^{\prime}$ for the direction and 0.5 
nT for the field strength. No ground-based, continuously recording variometer was available on-site or within $2800 \mathrm{~km}$ for a temporal reduction of geomagnetic variations from external (magnetospheric, ionospheric) sources.

How do these observations fit to global geomagnetic field models? Three field models were used to investigate this. The first model is the phenomenological model of the solar quiet variation Sq by Campbell (2003) derived from observatory time series.

The second model is the comprehensive model CM4 by Sabaka et al. (2004) that is based on geomagnetic satellite data and observatory hourly mean values. This model describes the magnetic fields due to the core, the crust, the ionosphere, the magnetosphere, and due to secondary, induced currents in the mantle arising from ionospheric and magnetospheric currents. For values for the solar flux F10.7 we used the 3-monthly average centred on September 2004.

We calculate two different predictions of the field variations using CM4, denoted as 'CM4 without Dst' and 'CM4 with Dst', respectively. Both contain the daily ionospheric and magnetospheric field variations (and their Earth induced counterpart), but in addition the 'CM4 with Dst' also considers time-changes due to variations of the magnetospheric ring current as monitored by the Dst index. For 'CM4 without Dst' we excluded field variations caused by changes of the Dst-index since we at this point focus on the quiet-time daily field variation as predicted by CM4. (Note, however, that Dst also includes a quiet-time, slowly varying field in the form of the ever present ring-current.) This also makes the model predictions more compatible with those of the Sq-model by Campbell (2003). 'CM4 with Dst' was calculated to estimate the influence of the non-regular magnetospheric field changes at Tristan da Cunha. Provisional values for Dst, provided by the WDC for Geomagnetism, Kyoto, were used for the calculation. The location of the observatories used to derive the Dst-index are indicated in fig. 1.

The third model is IGRF-10 (Maus et al., 2005), which is a main field model that covers the period 1900.0 to 2010.0 .

\section{Results}

On Sept. 27 and 29, a total of 3 declination measurements, 2 inclination measurements and 12 total field measurements were made (cf. the diamonds in fig. 2). The results are consistent, but the difference of 0.15 degree between successive declination measurements on Sept. 29 by far exceeds reasonable measurement errors (fig. 2). The same applies to the total field measurements on Sept. 29, which scatter by about $15 \mathrm{nT}$ (fig. 2). These observed differences are believed to represent the temporal variation of the geomagnetic field.

In lieu of an on-site variometer or close-by geomagnetic observatory, the temporal variation expected for the location and the given date is calculated from the various global models mentioned in the previous section. Note that the offset of the model results (full line for Sqmodel by Campbell (2003); short-dashed line for CM4 without Dst; long-dashed line for CM4 with Dst) shown in fig. 2 is arbitrary: all model curves are adjusted to fit the level of the measurements of Sept. 27, and the obtained offset was also used for Sept. 29.

\section{Discussion}

From the planetary index of geomagnetic activity, Kp, shown in the top of fig. 2, the geomagnetic field condition for Sept. 27 and 29, 2004 , is rather quiet, and the geomagnetic variations are mainly due to the solar quiet daily variation (ionospheric Sq-currents). Kp was 2o during the measurements of Sept. 27, Kp was $1+$ during the time of the measurements on Sept. 29, and did not exceed $\mathrm{Kp}=2+$ during those two days. The Dst index is between $6 \mathrm{nT}$ and $-22 \mathrm{nT}$ on Sept. 27 and between $4 \mathrm{nT}$ and $5 \mathrm{nT}$ on Sept. 29, which also indicates low geomagnetic disturbance. This can be seen in fig. 2 by the similarity of the variations calculated for 'CM4 without Dst' (short-dashed line) and 'CM4 with Dst' (long-dashed line). The greatest difference between the two model curves is observed prior to and after the declination and inclination measurements on Sept. 27, but not during these measurements. 

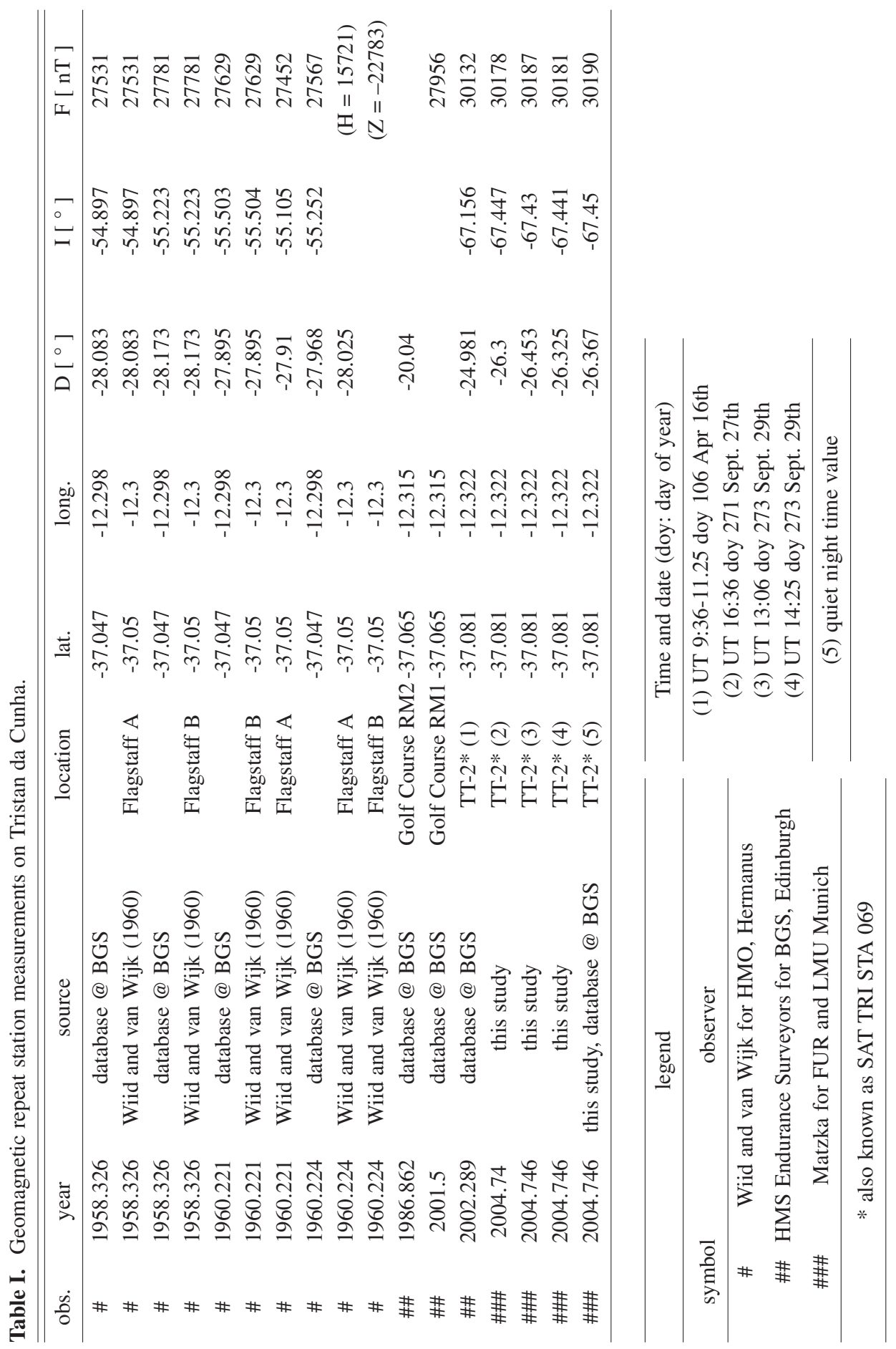
The measurements of D and I for Sept. 27 and 29 are equally well fitted by the Sq-model by Campbell (2003) and by the two CM4 predictions (fig. 2), confirming that the geomagnetic variation on Tristan da Cunha at that time is largely described by the solar quiet-time daily variation. Note, however, that the model of Campbell (2003) and CM4 do not agree well between 1600 and 2400 UT for declination. Unfortunately, there are no declination measurements for this time period to decide which model is preferable. The total field $\mathrm{F}$ variation is better described by the CM4's than the Campbell (2003) model. Adjusting the offset for the Campbell (2003) model for the total field measurements of Sept. 27, 1600 UT (when Dst $=-2 \mathrm{nT}$ is small), gives a significant misfit to the data measured between 1200 UT and 1500 UT on Sept 29 (when $-4 \mathrm{nT} \leq$ Dst $\leq 0 \mathrm{nT}$ is similarly small). The reason for this behaviour is basically that the 'CM4 without Dst' has its daily minima around $1540 \mathrm{UT}$, whereas the Campbell (2003) model gives the minima around 1400 UT. There is some scatter in the total field measurements on Sept. 27, that is qualitatively resembling the variation of ' $\mathrm{CM} 4$ with Dst', but with a higher amplitude (fig. 2). This could be attributed to short term magnetospheric variations that are visible in the total field spot readings, but attenuated in the Dst hourly mean values.

One possibility to explain the difference of the Campbell (2003) model from CM4 and the measurements is the fact that the Campbell (2003) model relies solely on geomagnetic observatory data. It is therefore probably biased in the South Atlantic region towards geomagnetic observatory data from continental coastal locations. The Sq-variation in the $\mathrm{Z}$ component (that would affect mostly $F$ in fig. 2) from coastal geomagnetic observatories can be significantly influenced by induced electric currents in the ocean and their missing counterparts in the less conductive continental crust so they do not geometrically cancel out (Olsen and Kuvshinov, 2004; Kuvshinov et al., 2007). In return it can be expected that a geomagnetic time series from an island location like Tristan da Cunha (for which channelling of the induced currents is much less serious than for a coastal station, leading to a smaller anomalous induction field) would be a valuable addition for quantifying and studying the Sq-variation in the SAA.

Since CM4 fits the repeat station data better, and since Dst was small during the measurements, we use the 'CM4 without Dst' to determine quiet night time levels for our repeat station measurements. These are $\mathrm{D}=-26^{\circ} 22^{\prime}, \mathrm{I}=$ $-67^{\circ} 27^{\prime}$, and $\mathrm{F}=30190 \mathrm{nT}$. The repeat station results for 2004 are the latest reported repeat station results for Tristan da Cunha (as of March 2008). The results are compared to those from previous years in table I and fig. 3. Previous data were retrieved from original literature as well as from the World Data Centre for Geomagnetism, Edinburgh, maintained by BGS. The original repeat station by Wiid and van Wijk (1960) was destroyed by a lava flow (locations Flagstaff A and Flagstaff B, which were a few meters apart from each other, see table I). Later measurements by surveyors of HMS Endurance made for BGS were done at three different locations (RM2, RM1 and TT-2, see table I).

The measurements from 2004 were conducted on TT-2, the last site occupied by surveyors of HMS Endurance in 2002 (Riddick, pers. comm.). The scatter of the repeat station measurements and the poor agreement with IGRF-10 (Maus et al., 2005) seen in fig. 3 is easily explained by the different locations of the observations. Tristan da Cunha is a volcanic island with strongly magnetised rocks and this leads to spatially varying crustal field contribution. It is therefore necessary to conduct geomagnetic measurements at the same location. Whilst this is emphasized to the HMS Endurance surveyors in their training from BGS the existence of several marked sites on Tristan da Cunha within close vicinity of one another has led to some confusion in the past. Another problem is that the local bias field can change with time, for instance due to volcanic activity, erosion, magnetisation of the volcanic rocks due to lightning strikes, or a variation of the rock magnetisation with temperature. The local bias field is also very inhomogeneous and slight positional changes (e.g. in the height of the sensor) have effects. 


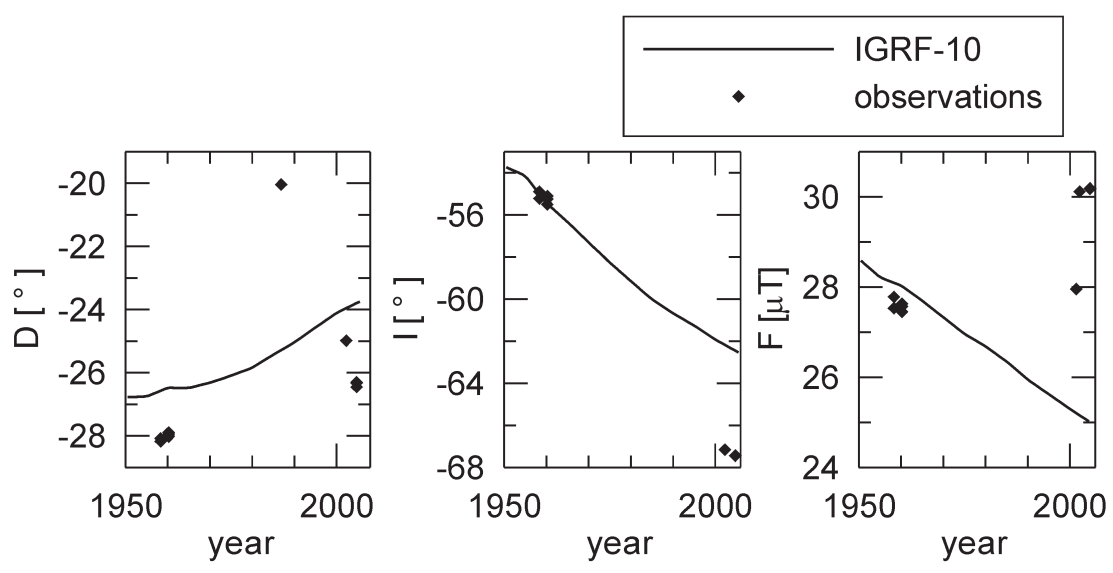

Fig. 3. Comparison of repeat station measurements on Tristan da Cunha with IGRF-10 (Maus et al., 2005). The large scatter of the observations is due to several relocations of the repeat station (see text and table I) in the presence of large spatial gradients of the crustal field.

\section{Conclusions and outlook}

Magnetic repeat station measurements on Tristan da Cunha in the South Atlantic under magnetically quiet conditions from Sept. 27 and 29, 2004 have been described, and the results reduced to quiet midnight values by using geomagnetic variations calculated from CM4 (Sabaka et al., 2004). These are $\mathrm{D}=-26^{\circ} 22^{\prime}, \mathrm{I}$ $=-67^{\circ} 27^{\prime}$, and F $=30190$ nT. Significant differences in the calculated solar quiet variations for Tristan da Cunha were found between the model by Campbell (2003) and CM4 and are attributed to induction effects present in the Campbell (2003) model.

It is argued that Tristan da Cunha represents an ideal location to continuously record geomagnetic field variations for studying the SAA. Firstly, the island is central to the present gap in the geomagnetic observatory network. Secondly, induction effects are less pronounced for an island than for a continental coastal location. Thirdly, the island's geomagnetic latitude is ideal for the separation of the field due to ionospheric Sq-currents and variations from the magnetospheric ring current.

We have received funds from the Danish Natural Science Research Council to establish and maintain a magnetometer station on Tristan da Cunha. The aim of this project is to provide continuous high-quality time series of the field variations prior and during the Swarm satellite mission (Friis-Christensen et al., 2006), allowing for better investigations of the special geomagnetic conditions of the SAA by combining ground and satellite data. The set up of the ground station will receive significant support from the Geomagnetism Program of the USGS. It is planned to install a temperature controlled and suspended FGE three-component fluxgate magnetometer on a concrete pillar for $1 \mathrm{~Hz}$ recording of the full geomagnetic vector. A hut will be built for weekly absolute measurements with a DI-flux and an Overhauser magnetometer and baselines will be determined for the FGE. If the local crustal field is not constant over the whole period (several years) of observations (e.g. because of geological processes like the volcanic eruption from 1961 (Baker et al., 1964)), the secular variation determined from the ground station alone will be affected. It is expected that this possibly time-varying station bias will be better determined with the help of a satellite-derived geomagnetic field model. Ground station data from Tristan da Cunha will still be of great value since they provide information on short-term geomagnetic variations (e.g. solar quiet, magnetospheric ring current), that are essential ingredients for deriving advanced geomagnetic field models. 


\section{Acknowledgements}

We would like to thank the two reviewers for their helpful comments. JM would like to thank James Glass and Jeremy Green for their help with the measurements. The government of Tristan da Cunha, and especially Anne Green and Mike Hentley are thanked for the permit and support of the measurements. The crew and officers of SA Agulhas and CHC Africa are thanked for their logistical support. Thanks to Martin Feller and Werner Bauer from Geophysical Observatory Fürstenfeldbruck (FUR) and to Marko Leitner for their help with the preparation of the repeat station measurements. The measurements were conducted with funds from FUR during a stay of JM on Tristan da Cunha that was supported by Deutsche Forschungsgemeinschaft (DFG).

\section{REFERENCES}

Baker, P.E., I.G. Gass, P.G. Harris And R.W. Le Maitre (1964): The volcanological report of the Royal Society Expedition to Tristan da Cunha, 1962, Phil. Trans. $R$. Soc. Lond. A, 256-A, 439-578.

CAMPBELL, W. (2003): Introduction to geomagnetic fields, (Cambridge University Press, $2^{\text {nd }}$ Ed).

FriIs-Christensen, E., H. LÜHr and G. Hulot (2006): SWARM: A constellation to study the Earth's magnetic field, Earth Planets Space, 58, 351-358.

Gubbins, D., A.L. Jones and C.C. Finlay (2006): Fall in Earth's magnetic field is erratic, Science, 312, 900-902.

Heirtzler, J., H. Allen and D. Wilkinson (2002): Everpresent South Atlantic Anomaly damages spacecraft, EOS, Transactions American Geophysical Union, 83, 156-173.

Hulot, G., C. Eymin, B. Langlais, M. Mandea and N. OLSEN (2002): Small-scale structure of the geodynamo inferred from Ørsted and Magsat satellite data, Nature, 416, 620-623.

Hulot, G., T.J. SabaKa and N. Olsen (2007): The Present Field, in Treatise of Geophysics, edited by G. SCHUBERT (Elsevier, Amsterdam), Volume 5, Chapter 2.

JANKOWSKI, J. and C. SUCKSDORFF (1996): Guide for Magnetic Measurements and Observatory Practice, (Inter- national Association of Geomagnetism and Aeronomy, Warsaw), pp. 235.

Korte, M., M. Mandea, H.J. Linthe, P. Kotze and E. RiCALDI (2009): New geomagnetic field observations in the South Atlantic Anomaly region, Annals of Geophysics, this issue.

Kuvshinov, A., C. ManoJ, N. Olsen and T. SABAKa (2007): On induction effects of geomagnetic daily variations from EEJ and Sq sources at low and middle latitudes, J. Geophys. Res., 112, B10102, doi:10.1029/2007JB004955.

LE, G., C.T. Russell and K. TAKAHASHI (2004): Morphology of the ring current derived from magnetic field observations, Ann. Geophys., 22, 1267-1295.

Macmillan, S., C.W. Turbitt and A. Thomson (2009): Ascension and Port Stanley geomagnetic observatories and monitoring the South Atlantic Anomaly, Annals of Geophysics, this issue.

Matzka, J. and T.L. HAnsen (2007): On the various published formulas to determine sensor offset and sensor misalignment for the DI-flux, Publs. Inst. Geophys. Pol. Acad. Sc., C-99 (398), 152-157.

Maus, S., S. Macmillan, T. Chernova, S. Choi, D. Dater, V. Golovkov, V. Lesur, F. Lowes, H. LÜHr, W. MaJ, S. Mclean, N. Olsen, M. Rother, T. Sabaka, A. THOMSON and T. ZVEREVA (2005): The 10th generation international geomagnetic reference field, Geophys. $J$. Int., 161, 561-565.

NewitT, L.R., C.E. BARTON and J. BitTerly (1996): Guide for magnetic repeat station surveys (International Association of Geomagnetism and Aeronomy) pp. 112.

Olsen, N. and A. Kuvshinov (2004): Modeling the ocean effect of geomagnetic storms, Earth Planets Space, 56, 525-530.

Olsen, N. and M. Mandea (2006): A new approach to directly determine the secular variation from magnetic satellite observations, Geophys. Res. Lett., 33, L15306, doi:10.1029/2006GL026616.

Olsen, N., H. LÜHR, T.J. SABAKA, M. MANDEA, M. Rother, L. TøFFnER-ClAusEn and S. CHOI (2006): CHAOS - a model for the Earth's magnetic field derived from CHAMP, Ørsted, and SAC-C magnetic satellite data, Geophys. J. Int., 166, 67-75.

RIDDICK, J. (pers. comm.): in the form of a note entitled: Magnetic Surveys in the South Atlantic 2003 (British Geological Survey), Version 1.0.

Sabaka, T.J., N. Olsen and M.A. Purucker (2004): Extending comprehensive models of the Earth's magnetic field with Ørsted and CHAMP data, Geophys. J. Int., 159, 521-547.

WIID, B.L. and A.M. VAN WIJK (1960): Geomagnetic observations on Marion Island, Gough Island and Tristan da Cunha, Trans. Roy. Soc. S. Afr., 36-2, 107-117. 